\title{
Zwei Fälle von Ulous perforans corneae nach Conjunctivaltripper. (Tripperkokken im Gewebe.)
}

\author{
Aus der Augenklinik von Prof. A. Graefe zu Halle a. S. \\ von
}

Dr. M. Dinkler, Assistenzarzt an der medic. Klinik zu Heidelberg.

Hierzu Tafel III, Fig. 1-6.

Die Frage bezüglich der parasitären Natur der blennorrhoischen Schleimbaut-Catarrhe der Harn- und Geschlechtswege und der Augenbindehaut ist neuerdings durch die sorgfältige und ausführliche Monographie E. Bumm's: „der Mikroorganismus der gonorrhoischen Schleimhauterkrankungen: Gonococcus Neisser" (Bergmann, Wiesbaden I. und II. Auflage) einer endgültigen Entscheidung entgegengeführt worden; durch eine anf zahlreiche Sekretuntersuchungen sich stützende Beobachtungsreihe hat Bumm einmal das schon von vielen anderen Seiten bestätigte, regelmässige Vorkommen des von Neisser im Jahre 1879 beschriebenen Diplokokkus bei den in Frage stehenden Schleimhautaffectionen wiederum constatirt, zugleich aber auch - und darin liegt der Schwerpunkt der Arbeit - durch die Reincultivirung dieser Mikroorganismen und deren erfolgreiche Ueberimpfung auf empfängliche 
Schleimhäute die beiden anderen nach der R. Koch'schen Lehre für die Pathogenität einer Spaltpilzform unerlässlichen Faktoren beizubringen vermocht. Es geht dabei aus den ausführlichen Angaben über das wăhlerische Verhalten der Bakterien bezüglich eines zusagenden Nährbodens (Menschen-Blutserum), ferner aus den Schwierigkeiten, die dem Untersucher aus der kurzen Lebensdaner der gewonnenen Reineulturen erwachsen, und besonders weiterhin aus dem refractären Verhalten der gebräuchlichen Versuchsthiere genügend hervor, weshalb die in dieser Richtung angestellten Uutersuchungen zu keinem definitiven $\mathrm{Ab}$ schluss führen konnten; demn wenn auch F. Krause und andere unzweifelhaft Reinculturen von Tripperkokken gewonnen haben, so war es ihnen bei der erwähnten Immunität der Versuchsthiere und dem Mangel an mensehlichem Material doch nicht gelungen, durch erfolgreiche Inoculation der rein gezüchteten Mikroben das letzte Glied in die Beweiskette für die Pathogenität dieser Kokken einzufügen. Bumm vermochte durch Einführung geringer Mengen zweier Tripperkokken-Reinculturen in die Harnröhre zweier Frauen einen in jeder Beziehung typischen Urethral- und Blasentripper, in dessen Seeret die Kokken zahlreich vorhanden waren, zu erzeugen und damit die Discussion über die Neisser'schen Diplokokken zu einem überzengenden Abschluss zu bringen. - Ein weiteres Verdienst des genannten Autors ist es, die Tripperkokken im Gewebe nachgewiesen und mit Hülfe zahlreicher sorgfältiger Zeichnungen die einzelnen Stadien der specifischen Blennorrhoe gerade von diesem Gesichtspunkte aus beschrieben zu haben, denn über das Eindringen und die Verbreitung dieser Mikroorganismen in den einzelnen Geweben war, wie aus dem gesehichtlichen Referat der Monographie hervorgeht, bisher so gut wie nichts bekannt. Als Substrat für diese seine histologisch-bacteriologischen Untersuchungen benutzte Bumm kleine Stückchen Con- 
junctivalschleimhaut, die mit Bindehauttripper behafteten Neonatis und Erwachsenen entnommen waren. Das Studium sämmtlicher so gewonnener Präparate ergab ein völlig übereinstimmendes Resultat: Die Tripperkokken dringen vermöge einer intensiven Invasionsfähigkeit in die Saftspalten der mit Cylinderepithel bedeckten Schleimhäute ein und lösen durch ihre Ansiedelung und energische Wucherung in den einzelnen Fällen verschieden hochgradige Entzündungs - Erscheinnngen aus; dabei betont Bumm nachdrücklich, dass die Kokken nur zwischen Cylinderepithelien und in den ganz oberflächlichen Schichten des sich anschliessenden submucösen Bindegewebes sich zu vermehren vermögen; auf Plattenepithel und in den tieferen Schichten des Bindegewebes gelangen sie nicht zur Entwicklung. - Eine kleinere Anzahl (ca. 4 Falle) aus blennorrhoiseh inficirten Augen excidirter Conjunctivalstückchen gaben mir im Winter 1886 Gelegenheit, die Angaben Bumm's über das Verhalten der Kokken in der Bindehaut im vollsten Masse bestätigt zu finden. Dass ich das Resultat dieser NachUntersuchungen in extenso mitzutheilen abstehe, bedarf wohl bei der im Grossen und Ganzen erschöpfenden Beschreibung Bumm's keines weiteren Commentars. - So vollkommen nun auch die Uebereinstimmung der von mir beobachteten Conjunctival-Veränderungen mit den ron Bumm beschriebenen ist, so kann ich doch einer anderen wichtigen These, nämlich der Immunität der Plattenepithelmembranen und des Bindegewebes gegenüber einer Tripperinfection im Hinblick auf die bei Augenbindehauttripper verhältnissmässig immer noch häufige eiterige Entzündung der Hornhaut nicht beipflichten. Nach Bumm ist, wenn wir richtig folgern, die Cornea vor einer Tripperkokken-Invasion und deren Folgeerscheinungen dureh ihren mehrschichtigen, in seinen oberen Lagen ziemlich resistenten Plattenepithelüberzug absolut geschützt - und es würde 
H. Dinkler.

demnach die klinische Beobachtung zur Erklärung dieser Hornhautvereiterung in ätiologischer Beziehung eine Mischinfection, in welcher man in neuerer Zeit den Schlüssel für zablreiche, bisher gar nicht oder falsch gedeutete Complicationen der einzelnen Infectionskrankbeiten gefunden hat, anzunehmen gezwungen sein. Die Möglichkeit einer derartigen Annahme ist ja nach Analogie anderer Infectionskrankheiten, wie z. B. der Diphtherie der Respirationswege, bei der bisweilen die primaren Infectionsträger im Laufe der Erkrankung auch durch andere Spaltpilze verdrängt zu werden scheinen, entschieden als berechtigt anzuerkennen, zumal, da das Auge, wie kaum ein anderes Organ, jeglichen Infectionen ausgesetzt ist.

Zwei durch Exenteration an Conjunctivaltripper (mit consecutivem schweren Ulcus corneae) leidender Augen gewonnene Präparate ermöglichten es mir, diesen theoretischen Ueberlegungen praktisch näher zu treten und mich mit der Frage, ob die Tripperkokken, oder die Eiterkokken $x a \tau \xi$ -

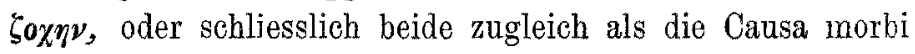
bei dieser Art von Hornhautvereiterung anzusehen sind, eingehender zu beschäftigen.

Bezüglich des klinischen Verlaufes dieser betreffenden Fälle sei kurz bemerkt, dass Präparat I von einem 2 jährigen Madchen, Bertha Franz, herstammt, welches mit ihren beiden anderen kleinen Geschwistern von einer an Genitaltripper leidenden älteren Schwester inficirt worden war; der Zustand der Hornhautaffection wurde sehon bald nach der Aufnahme in die Klinik ein so hoffnungsloser, dass die Exenteration indicirt erschien; über den Operationsverlauf und die Heilung ist nichts besonderes zu berichten. Das zweite Präparat ist dem Auge eines 22jährigen Maurers (Karl Eckebrecht aus Ringleben bei Artern) entnommen; derselbe litt seit einigen Wochen an Harnröhrentripper; 6 Tage vor seiner Aufnahme trat die Augenerkrankung ein. Bei der mikroskopisehen Untersuchung des eitrigen Secretes 
fanden sich ebenso, wie in dem Falle Bertha Franz, zahlreiche Tripperkokken. Die Schleimhaut der Lider war leicht diphterisch afficirt und es wurde, da die Cornea vereitert war, sofort die Exenteration vorgenommen; post operationem wurde der Verband unter Borsäureirrigation $3 \mathrm{mal}$ täglich gewechselt und Jodoform in den Bindehautsack eingestäubt. Heilung trat nach 4Tagen ein, sodass Patient schon am 11. Tage der Behandlung mit der entsprechenden Prothese entlassen werden konnte, - Die beiden Präparate wurden unmittelbar nach der Operation in absoluten Alkohol gelegt und unter mehrmaliger Erneuerung desselben sorgfältig gehärtet; behufs Anfertigung möglichst dünner und zugleich vollständiger Schnitte wurden sie in der bekannten Weise in Celloidin eingebettet.

Ehe wir uns der Beschreibung der mikroskopisehen Veränderungen zuwenden, noch einige Worte über das zakroskopische Bild. An Präparat I fällt zunächst auf, dass die Iris mit der Hornhant in toto zu einem einheitlichen Ganzen verschmolzen ist und ihre durch die Topographie gegebene Function als die hintere und vordere Kammer bildendes Organ verloren hat; nur in der äussersten Peripherie ist zwischen Cornea und Iris noch ein schmaler Spaltraum nachweisbar. Die centralen Schnitte zeigen ferner, dass die Hornhaut einen beträehtlichen Defect, welcher der klinischen Beobachtung entsprechend in der Richtung nach unten innen sich dem Limbus corneae am meisten nähert, erlitten hat; ein Theil dieses Substanzverlustes und zwar der nach oben gelegene ist durch eine mit Farbstoffen intensir sich imprägnirende Auflagerung ausgefüllt, die zum Theil das Niveau der anliegenden Hornhaut knopfformig überragt; die gleichmässige glatte Begrenzung der freien Cornealfläche ist dabei völlig geschwunden und Einfaltungen mit Hervorwölbungen wechselnder Grösse lassen sich besonders im unteren Segment nachweisen. Auch das Gesammtvolumen der Cornea hat bei der hochgradigen eiterigen Zer- 
störung eine beträchtliche Reduction erfahren, die zu Folge des Collapses nach der Perforation und dem Aufhüren des Kammerwasserdruckes noch viel mehr hervortritt. Zwischen dem durch Verschmelzung von Cornea und Iris entstandenen Gebilde einerseits und der linse, resp. der vorderen Linsenkapsel andererseits, also dem unter normalen Verhältnissen der hinteren Kammer entsprechenden Raum, dessen Höhendurchmesser um ein Vielfaches vergrössert erscheint, liegt weiterhin eine leicht granulirte, netzartig angeordnete Masse, die beim Zexzupfen eine mittlere Cohaerenz fühlen lässt. Linse und Linsenkapsel und der vordere Theil des Uvealtractus zeigen makroskopisch, abgesehen von der durch den Prolapsus iridis et lentis bedingten Verlagerung und Verschiebung der einzelnen Theile nach vorn keine bemerkenswerthen Veränderungen. - Um bei der mikroskopischen Beschreibung ein möglichst deutliches und in den Details genaues Bild entwerfen zu können, sollen die einzelnen Organtheile, Cornea, Iris, vordere und hintere Kammer etc. hinter einander, sowohl vom histologischen wie bakteriologischen Standpunkt aus gewürdigt werden. - Die schon bei Lupenvergrösserung wahrnehmbare Dnregelmässigkeit in der Oberflächenbegrenzung der Cornea zeigt sich mikroskopisch, abgesehen von den das ganze Organ betreffenden Faltungen, einerseits durch Substanzdefecte, andererseits durch entzändliche Auflagerungen und Gewebew ucherung bedingt. Das HornhautEpithel ist zum Theil gänzlich verloren gegangen, und zwar ist der Defect an den Schnitten grössten Durchmessers, also den central gelegten, am grössten. Das in der Peripherie des Substanzverlustes erhaltene Epithel zeigt nirgends nur einigermassen die normale dreischichtige Anordnung der in der Tiefe cylindrisch-cubischen, in der Mitte polyedrischen und an der Oberfläche planen Comealepithelzellen gewahrt; bald findet man die Epithelmembran nur aus cubischen oder annähernd cylindrischen Zellen gebildet, bald sind die Zellen wiederum stark abgeplattet und in ihrer Begrenzung so verwaschen, 
dass sie geradezu zu einer gleichmässigen, nur von strichförmigen Kernen unterbrochenen homogenen Membran verschmolzen erscheinen. An den letzteren, fast ausschliesslich peripher gelegenen Stellen bilden kanm 3-4 Zelllagen den Epithelüberzug; dieser beträchtlichen Reduction des Epitheldurchmessers steht an anderen Stellen eine ebensolche Frhöbung gegenüber, denn zahlreiche Parthien lassen eine Vermehrung der normalen 5-6 Zellschichten um das dreiund mehrfache erkennen. Diese offenbare und auffällige Hyperplasie findet ferner nicht in Form papillärer Excrescenzen über das Niveau der Umgebung ihren Ausdruck, sondern gelangt vielmehr in Form zapfenartiger, in die Tiefe dringender Fortsätze, deren Ausbreitung auf Kosten des subepithelialen Hornhautgewebes, also zunächst der Basalmembran und des Hornhautparenchyms erfolgt, zur Beobachtung. Als das anatomische Substrat für diese anffallende Epithelwucherung finden sich überall oft dicht an einander gedrängt in Karyokinese befindliche Zellen, an denen man die bekannten mitotischen Processe mit seltener Deutlichkeit und Schönheit verfolgen kann. Besonders häufig unter den Kernfiguren ist eine Form, die der allgemein als Anfangsform anerkannten Knänelform offenbar äquivalent, wegen ihrer eigenthümlichen Kernstructur besonders Erwähnung verdient: an Stelle des bekannten mehr oder weniger dichten Convolutes von Kernfäden findet man nämlich bisquitförmig gestaltete Körner, die erstens in ganz regelmässigen Abständen zu einander liegen und zweitens mit ihrer Längsaxe radiär za einem ideellen, dem Centrum des ganzen Zellkörpers etwa entsprechenden Mittelpunkt aufgestellt erscheinen. Bei eingehender Beobachtung lässt sich weiterhin mit Sicherheit constatiren, dass diese Körner der Kernsubstanz hohlkugelartig im Imern des Protoplasmas angeordnet sind, denn bei einer gewissen Objectiveinstellung sieht man die Körner deutlich achter- oder bisquitförmig gestaltet und radiär gestellt, und innerhalb dieser 
kreisförmig aneinandergereihten Exemplare einen hellen, kaum granulirten Raum; bei höherer resp. tieferer Einstellung des Objectives jedoch treten auch in diesem hellen Raume Körner von gleicher Färbung mit voller Deutlichkeit hervor, die der Auffassung von der schalenförmigen Anordnung entsprechend nicht eine achterformige, sondern vorwiegend runde Configuration erkennen lassen, weil man nur die Pole dieser Kerntheile im Flächenbild des Mikroskopes entworfen sieht. ${ }^{*}$ ) Diese eigenthümliche Anordnung der chromatischen Kernsubstanz legt besonders an den mit Anilinfarben behandelten Schnitten den Gedanken nahe, dass es sich überhaupt nicht um Kernbestandtheile, sondern um endocellulär gelegene Kokken handelt; allerdings macben die bei einem genaueren Vergleich hervortretenden Differenzen in der Grösse, ferner die eigenthümliche Regelmässigkeit in der Anordnung der einzelnen Körner eine solche Annahme wenig wahrscheinlich. Ausschlaggebend ist das Verhalten der fraglichen Elemente gegenüber den, nur die Kerne imprägnirenden Farbstoffen, wie z. B. dem Carmin; während bei Färbung mit Anilinwasser-Methylviolett zwisehen Kokken und diesen Kernsubstanzen nur in der Nüancirung ein Unterschied bemerkbar ist, insofern als die Kokken einen etwas helleren, mehr dem „Blau” sich nähernden Farbenton annehmen, gegenüber den mehr violetten Theilen der Kernsubstanz, so bleiben bei einfacher Carminfärbung die wirklichen Kokken völlig ungefärbt, die Kernsubstanz jedoch, zu deren characteristischen Eigenschaften während des Theilungsvorganges eine gesteigerte Affinität zu fast allen Farbstoffen gehört, nimmt das Carmin in intensiver Weise auf. - Es handelt sich offenbar bei dieser abnormen Configuration der Kernsubstanz nur um eine pathologische Spielart oder Varietät von der gewöhlichen Knäuelform, deren Entstehung vielleicht von einer beson-

*) Fig. 1 a. 
deren Eigenschaft des entzündlichen Reizes abhängig ist. An den übrigen Kernfiguren der Aequatorialplatte mit ihrem feinen achromatischen Faserkorb, der doppelten Kernplatte und den weiteren Stadien bis zur vollendeten Zweitheilung sind keine belangreichen Abweichungen von dem bekannten Typus nachzuweisen; drei- oder mehrfache Kerntheilungsfiguren sind nirgends zu constatiren gewesen und scheint mir bei der Häufigkeit dieser Beobachtung in ähnlichen Fällen die Annahme nicht ganz unberechtigt, dass im Grossen und Ganzen die Zweitheilung der Zellen für regenerative Neubildung im Gegensatz zur Mehrtheilung bei idiopathischer, d. h. Geschwulst bildender Hyperplasie charakteristisch ist. - Das Protoplasma der in Kerntheilung befindlichen Zellen zeigt, abgesehen von der feineren Granulirung bisweilen eine deutliche Ausbildung concentrischer Streifen, welche im äusseren Drittel des Zellleibes mehrfach hinter einander geschichtet, bei der Färbung mit Anilinfarben gleichmässig imprägnirt hervortreten; diese Streifen umfassen jedoch anscheinend nicht die ganze Zelle, sondern nur eine schmale, gürtelförmige Parthie derselben *), und ist ihre Entstehung gewiss als ein Beweis für tiefgehende Aenderungen in der Cohäsion der Zellmoleküle und der elementaren Zusammensetzung des protoplasmatisehen Inhaltes der Zellen während der mitotischen Processe zu verwerthen. Ein weiteres, für diese irtracellulären Vorgänge bei der Karyokinese wichtiges Verhalten kommt in dem Auftreten sichelformiger Lücken in der Umgrenzung der in Theilung begriffenen Epithelien *) zum Ausdruck; offenbar ist während des Theilungsvorganges die Vascularisation der Zelle, der Flüssigkeitsgehalt des Protoplasmas und des Kernes derartig gesteigert, dass sich die Wasserentziehung nach der Alkoholhärtung durch eine deutlich hervortretende Reduction des gesammten Zellvolumens mikroskopisch zu erkennen giebt.

Fig. 1 a. 
Neben diesen wesentlich im Innern der Zellen sich abspielenden Veränderungen gehen gleichfalls auffallende an der äusseren Begrenzung und gegenseitigen Verbindung einher. Man findet nämlich zwischen den Epithelien, anstatt der minimen Intercellularsubstanz, die normaliter in Form feinster Kittleisten die feste Ineinanderfugung der Zellen zu garantiren scheint, stellenweise netzartig angeordnete Spalträume *) ron sehr verschiedenem Caliber; in dieselben ragen gleichsam morgensternartig die Stachelfortsätze der Epithelzellen hinein.*) Schon diese Beobachtung der Riffzellen, welche auch an dem Epithel der äusseren Haut bei gewissen entzündlichen oder rein neoplastischen Ernährungsstörungen, an der Hornhaut in specie im Gefolge von Ulcus serpens, Phthisis bulbi, Pemphigus etc. regelmässig aufzutreten scheinen, spricht für eine hochgradige Lockerung des Epithelgefüges; noch mehr wird dieselbe jedoch exemplificirt durch das Auftreten eines interepithelial gelegenen, theils plastischen, theils cellulären Exsudats*), von denen das erstere an vielen Stellen einen getreuen Ausguss der Spalträume liefert; an anderen Stellen dominiren die Fiterzellen, die offenbar, wie jedes andere Exsudat der Oberflache, als der Stelle des geringsten Druckes zustrebend, auf ihrer Permigration durch das Epithel, durch die Alcoholeinwirkung fixirt sind; bei der proteusartigen Vielgestaltigkeit und der fast unbegrenzten Anpassungsfähigkeit dieser mit Eigenbewegung ausgerüsteten Zellen fällt ihre meist sternförmige Gestaltsveränderung nicht weiter auf. Meist liegen die Eiterkörper derartig zwisehen den Epithelien, dass die Kernanschwellung an dem Vereinigungspunkte mehrerer interepithelialer Saftspalten sichtbar ist, und von da aus die Protoplasmafortsätze nach verschiedenen Richtungen auseinanderstreben. An einzelnen Stellen zeigen sich ferner von den erwähnten Exsudaten völlig differente Einlagerungen in Form von fein-

*) Fig. 1 b $\mathrm{x}, \mathrm{c}$ 
körnigen Zügen, deren Verhalten gegenüber den Anilinfarbstoffen so vollkommen dem der Mastzellen gleicht, dass man sie wohl als direkte Derivate dieser Zellen, vielleicht dureh Berstung solcher zelliger Gebilde entstanden, mit Recht ansehen kann. - Die Gesammtwirkung aller dieser Veränderungen der Lockerung des Zellgefüges, der Exsudateinlagerungen ete., die für die Verbreitung der Tripperkokken von Wichtigkeit sind, vereint sich mit der Wucherung der Epithelzellen zu der eingangs hervorgehobenen auffallenden Hyperplasie des Epithelüberzuges der Cornea. Der Aussenfläche des Epithels liegen an einzelnen Stellen noch mehr oder weniger ausgedehnte Exsudate auf, die innerhalb ihres netzfơrmigen Gefüges von Fibrinbalken grosse blasige Zellgebilde einschliessen; diese letzteren zeigen nur zum Theil einen unzweifelhaft epithelialen Charakter, meist sind es, wie aus der kleinen, fast kreisrunden Form des gleichmässig tingirten Kernes und dem beträchtlichen Volumen des fast glashellen Protoplasmas hervorgeht, emigrirte weisse Blutkörper, die der Necrose und consecutiven Imbibition mit Lymphe verfallen, eine hyaline Degeneration ihres Protoplasmas erfahren haben. Gerade diese Elemente finden sich in Ausschwitzungen oder überhaupt bei entzündlichen Affectionen bekanntlich sehr hänfig. - Die Unregelmässigkeit an der inneren Grenze des Epithels wird, wie schon oben erwähni, durch zapfenartige, gegen die Substantia propria corneae vordringende Zellwucherungen bedingt und zeigt an den einzelnen Stellen eine sehr verschiedene Intensität. Die Zusammenfügung und Configuration der einzelnen Epithelien zu diesen schlauchförmigen Einwucherungen ist dabei oft eine so eigenthümliche, dass sie den zwiebelschalenförmigen Bau der für die Epitheliome charakteristischen Hornperlen vollkommen nachbildet. Auch diese Beobachtung ist nur im Sinne einer beträchtlichen Zellwucherung und zugleich auch als Analogon zur Entwickelung der erwähnten Hornkugeln der Epitheliome oder 
z. B. auch der Kernsubstanz der Crystallinse des Anges 7.u verwerthen; bei allen diesen Processen ist das primäre immer eine Wucherung der peripher gelegenen Zellen, die ibrerseits bei der Constanz des Raumes eine Zusammendrängung der einzelnen Zellelemente zur Folge haben muss; als secundäre Erscheinung tritt dann erst die degenerative Atrophie der älteren, stets central gelegenen Zellen ein; zugleich ist dieser Befund der schalentörmigen Aneinanderfügung und hyalinen Degeneration der Hornhautepithelien für die, wenn auch selten vorkommende, norphologische Gleichartigkeit gutartig regenerativer und malign-hyperplastischer Processe äusserst instructiv.

Das Verbalten der Tripperkokken gegenüber der Epithelschicht ist in allen Präparaten gleichmässig und entspricht im Wesentlichen dem gegenüber dem Cylinderepithel der Conjunctiva. Die Tripperkokken - ihre Legitimirung als solche wird später eingehend erfolgen liegen sowohl frei auf der Oberfläche der Epithelien als anch zwischen denselben; in den dem Stratum epitheliale aufliegenden Exsudatmassen finden sie sich theils in dem Protoplasma der Eiterkörper, theils zwischen diesen Zellen in reihenformig angeordneten Colonieen von verschiedenster Grösse. Ihre Häufigkeit ist mannichfachen Schwankungen unterworfen; an der einen Stelle findet man kleine Häufchen ron Kokken in grösserer Zahl, an anderen Stellen werden sie zwar seltener angetroffen, aber in um so mächtigeren Verbänden. Auf den oberflächlichen, meist abgeplatteten Epithelien sind sie an circumseripten Stellen in so grosser Zahl vorhanden, dass man einen Theil einer Reincultur vor sich zu haben glaubt; auch in diesen grossen Haufen ist die charakteristisehe Form der Diplokokken, die sich treffend mit zwei, mit ihren planen Seiten aneinander liegenden Kaffeebohnen vergleichen lassen, leicht nachweisbar. Von diesen Pilzrasen gehen Ausläufer innerhalb der interepithelialen Safstpalten mehr oder weniger 
weit in die Tiefe, die sich an einzelnen Schnitten in äusserst übersichtlicher Weise bis an die innere Grenze des Epithels verfolgen Iassen; im Inneren der Epithelzellen kommen sie nicht vor, dagegen scheinen sie der Aussenfläche derselben ziemlich fest $\mathrm{zu}$ adhäriren, da sie an zahlreichen Stellen trotz des vielfachen Hin- und Herschüttelns der Schnitte während der Färbung in grösseren Haufen an den abgeplatteten oder cubischen Epithelien der Oberflache haften geblieben sind. Die Wucherung in die Tiefe erfolgt innerhalb der Saftspalten, wie schon erwähnt, und zwar um so ungehinderter und freier, je grösser der Querschnitt derselben ist. Endocellulär liegen die Kokken im Epithelüberzug der Cornea nur vereinzelt in den Eiterkörpern des interepithelialen Exsudates. - Es dringen sonach die zunächst auf der Oberfläche des Epithels sich ansiedelnden und vermehrenden Tripperkokkenhaufen zwischen den Epithelzellen in die Tiefe und durchsetzen in wechselnder Menge sämmtliche Zellschichten; einer weiteren Wucherung scheint sich dann die vordere Basalmembran als impermeable Schicht wirksam entgegen zu stellen, denn an den Stellen, wo die Tripperkokken hinter der erhaltenen Basalmembran angetroffen werden, ist die Invasion, wie aus der Untersuchung der betreffenden Sehnittserie hervorgeht, von einer benachbarten, der Basalmembran beraubten Stelle oder vom Geschwürsrande aus erfolgt. - Die Basalmembran ist nicht nur im Bereiche des Ulcerationsdefectes, sondern auch in der Peripherie desselben - wenigstens stellenweise - geschwunden; bemerkenswerther Weise fehlt sie an zahlreichen Stellen unter einer mehrschichtigen Epitheldecke. Es erfolgt das Schwinden, wie sich unschwer constatiren lässt, unter dem Bilde der eiterigen Einschmelzung in der Weise, dass in die meist beträchtlich gequollene Membran von dem Hornhautparenchym aus Eiterkörper eindringen und ganz analog den Osteoklasten bei Knochenusurirung, nach verschiedenen Seiten feine v. Graefe's Arehiv rür Ophthalmologie, xXXIV. 3. 
spitz endigende Protoplasmafortsätze in die hyaline Grundsubstanz entsendend, die Resorption einleiten; an anderen Stellen sind die Eiterzellen schon zahlreicher eingedrungen und haben einen entsprechend grosseren Theil der Membran aufgelöst, und so lässt sich der Einschmelzungsprocess stufenweise bis zur völligen Defectbildung verfolgen. An den noch erhaltenen Theilen der Basalmembran, und zwar besonders an den aufgequollenen und verdickten Stellen kommen feine strichförmige Linien*), deren auffallend regelmässige Anordnung an den bekannten Bau der Echinokokkusmembran erinnert, oder schliesslich ausgeprägte Spalten zum Vorschein, Veränderungen, welche den fibrillären Bau der Membran und damit die entwickelungsgeschichtliche Deutung derselben als Derivat des Hornhautbindegewebes $\mathrm{zu}$ bestätigen scheinen; ganz besonders deutlich tritt diese fibrilläre Structur an den freien, dem Ulcus zugekehrten Enden der Membran hervor; man sieht sie nämlich an diesen Stellen geradezu in einzelne Bündel zerlegt, die an ihrer Basis verhältnissmässig breit, an ihrem freien Ende, durch den eiterigen Process aus ihrer gegenseitigen Verbindung gelöst, als zarte Fortsätze auslaufen und von dem erhaltenen Grundstock der Membran fimbrienartig auseinanderstreben. Ebenso wie an der Epithelschicht und der vorderen Basalnembran treten auch an dem Hornhautparenchym zahlreiche tiefgreifende Aenderungen, theils destructiver, theils regenerativer Natur hervor, nur an der äussersten Peripherie nahe dem limbus corneae findet man ein gegen den Grund des Geschwüres spitzwinkelig abfallendes Stück erhalten, das noch deutlich lamellärer Structur, nur durch eine starke zellige Infiltration und reiche Gefässbildung von der Norm differirt. Der im Wesentlichen central gelegene Defect in der Substantia propria ist zum Theil

*) siehe Fig. II. 
durch Exsudat, zum Theil durch gefässreiches Granulationsgewebe ausgefüllt. Das erstere besteht vorwiegend aus einem Grundstock leicht granulirter oder homogener Fäden, zwischen welchen zellige Elemente in wechselnder Menge eingelagert sind; die fadigen Bestandtheile dieses Exsudates werden, wie aus ihrer tinctoriellen *) und chemischen Reaction hervorgeht, aus Fibrin gebildet. Ein grösserer Theil dieser fibrinösen Substanzen zeigt eine völlig hyaline Degeneration, welche sich in der Umwandlung des leicht granulirten Faserstoffes in eine gleichmässige, im ungefärbten Zustande glänzende und stark Licht brechende Substanz zu erkennen giebt; auch die gerade für diese Transformation resp. Degeneration so charaktexistischen tropfenförmigen Anhängsel und Auswüchse der einzelnen Fibrinbälkchen sind reichlich vorhanden. Besonders dicht angehäuft ist das Exsudat an der des Epithels beraubten Parthie des Hornhautparenchyms und wirkt hier geradezu als Stützsubstanz des eiterigen Oberflachenbelages; unter dem Epithel dringt es in dickerer Lage nur auf eine kurze Strecke nach dem Limbus corneae zu vor. Chemisch lässt sich die Zusammensetzung der netzartig verzweigten Ausschwitzung mit Hülfe von Essigsäure etc. als der des Fibrines völlig entsprechend bestimmen, besonders schön und instructiv jedoç gelingt es, diese Faserstoff-Aussehneidungen sowohl zwischen den Epithelien, als auch an der freien Gesehwürsfläche mit Hülfe der von Weigert (Fortschritte der Medicin Jahrgang 1887, Heft 8) angegebenen Färbereaction darstellen; färbt man z. B. mit Carmin vor und dann mit einer Anilinwasser-Methylviolettlösung unter schliesslicher Entfärbung der so behandelten Präparate mit Lugol'scher Lösung und Anilinöl, so erhält man ein sehr zierliches Bild: in dem intensiv grünlichblau gefärbtem Gefüge der

*) Weigert, Fortschritte der Medicin. Jahrg. 1887, Heft 8. 
Eibrinbälkchen liegen die mit rothgefärbten Kernen versehenen Zellen verstreut; alle Gewebetheile ausser den Kernen sind farblos.

Das erhaltene Hornhautparenchym zeigt seinerseits ausser einer beträchtlichen Lockerung seines Gefüges eine starke kleinzellige Infiltration innerhalb der den normalen Saftspalten und Lacunen entsprechenden Räume und eine bervortretende Neubildung von centralwarts zwischen und parallel zu den einzelnen Lamellensystemen verlaufenden Gefässen. Die zelligen Elemente findet man entweder haufenweise in den Saftlakunen oder reihenweise zwischen den Bindegewebsbündeln, Verbindungsstränge zwischen den einzelnen Lakunen herstellend, bei einander liegend. Die Mehrzahl fon ihnen ist den Eiterzellen oder ausgewanderten weissen Blutzellen angehörig; die wenigen fixen Bindegewebskörper sind bei der Ueberzahl und intensiven Färbung der anliegenden Eiterzellen meist erst. nach längerem Suchen nachzuweisen. - Ein völlig anderes Gepräge als diese an die Sclera angrenzende Hornhautparthie zeigt der das Uleus begrenzende Parenchymtheil; der lamelläre Bau ist in Folge der eiterigen Einschmelzung der Bindegewebsfascikel geschwunden and wird ersetzt darch dicht an einander liegende, parallel $\mathrm{zu}$ einander gestellte Bindegewebszellen, deren Länge und stäbchenartige Kernform gegenüber der geringen Grösse der Eiterzellen plastisch hervortritt; das Protoplasma dieser Zellen lässt besonders an den Exemplaren eine beträchtliche Zunahme nachweisen, welche Kerntheilungsfiguren enthalten. Die Karyokinesen, deren Zahl auffallend gross ist, liegen nicht unmittelbar an der Geschwürsgrenze, sondern sind fast regelmässig durch eine zwei- oder dreifache Zellschicht von ihr getrenut, so dass sich die mitotischen Processe hinter dieser mehrfachen Zellschicht gleichsam wie hinter einem Wall der direeten Einwirkung des die Eiterung erregenden Principes entrückt, abzuspielen scheinen. Die 
einzelnen Kernfiguren lassen keine besonderen Eigenthümlichkeiten bezüglich ihres Baues erkennen; relativ am häufigsten ist die sogenannte "Tonnenform" mit ibren feinen achromatischen Verbindungsfäden und weiterhin die Knäruelfigur zu beobachten. - Was die Gefässneubildung in dem Hornhautparenchym und dem ihm angehorigen Theil der das Geschwür ausfüllenden Gewebsmasse anbetrifft, so erfolgt dieselbe vom Limbus corneae aus in Form von Capillaren, deren Richtung der Anordnung der Bindegewebslamellen entspricht; sie bestehen aus einem zarten Endo- und Perithelrohr, dessen einzelne Zellelemente sich aus grossen ovalen Kernen und einem feinkörnigen Protoplasma aufbauen. Die charakteristische byaline Transformation des Protoplasmas, wie sie den Endothelien völlig entwickelter Gefässe zukommt, ist durchweg noch wenig ausgesprochen. Zwischen den Endothelzellen trifft man hie und da weisse Blutkörper an, die in der Emigration begriffen, mit einem Theile ihres Protoplasma bereits zwischen den Gefässzellen durchgetreten sind. Die Annahme, dass intra vitam derartige Emigrationsvorgange sich zahlreich abgespielt haben, findet ihre weitere Bestätigung in der auffallend dichten Ansammlung von Leucocyten um die Capillaren herum. Innerhalb der Gefässe sind ausser geringen Mengen geronnenen Serums vorwiegend weisse Blutkörper vorhanden; rothe Blutkörper sind in den inneren Parthien des Hornhautparenchyms weniger zahlreich, während sie peripher in der Nähe des Limbus corneae überwiegen. - Besonderer Erwähnung verdient noch die äusserst wechselnde Volumenentfaltung der einzclnen Gefässe, die in Form von circumscripten und diffusen Varicositäten hervortritt; die spindel- oder sackförmigen Erweiterungen liegen stets an Stellen, an welchen es durch beträchtliches Auseinanderweichen der Lamellensysteme und Dilatation der Saftlakunen zu grösseren Spaltbildungen gekommen ist. Bei der Entstehung dieser Spalt- 
räume und der Ectasirung der Gefässe scheint ein Circ.vitiosus vorgewaltet zu haben insofern als, wahrscheinlich zunächst die entzündliche Lockerung des Hornhautparenchyms eine Gefăsserweiterung ermöglicht und begünstigt hat, dann aber der intravasculäre Druck eine weitere Steigerung der bindegewebigen Auflockerung bewirkt bat. Von den an die Oberfläche heranreichenden neugebildeten Gefässen aus erstrecken sich durch die Grenz- und Reactionszone der Substantia propria gegen das Uleus einzelne Ausläufer in die den Grund des Geschwürs ausfüllende, oben beschriebene Gewebsmasse, in welcher sie sich in Form zarter englumiger Canäle rielfach verzweigen und einen wichtigen Bestandtheil der Geschwürsmasse bilden. In der Umgebung der Gefässe findet man reichliche Zellanhäufungen, die zum Theil ans weissen Blutzellen, zum Theil auch aus unzweifelhatten Bindegewebszellen, Abkömmlingen der Perithelien oder fixen Hornhautkörper, bestehen; diese letztere Beobachtung wird gesichert durch das Vorkommen zahlreicher Kerntheilungs-Figuren und durch die morphologisehe Gleichartigkeit mit den erwahnten Zellformen. Auch äber die genaueren histologischen Details, welche bei der Gefässneubildung sich abspielen, lässt sich bei der Zartheit des Gewebes ein sicheres Urtheil bilden; man sieht nämlich bisweilen eine von den Zellen des Gefässrohres in einen langen, immer mehr sich verjüngenden, leicht granulirten Fortsatz auslaufen, der entweder in der Richtung auf ein anderes Gefäss zu spitz endigt oder auch, mit einem gleichen Fortsatz eines benachbarten Gefässes verschmelzend, zunächst noch ein solides, mehrere Kernanschwellungen beherbergendes Verbindungsglied zwischen zwei Gefässen darstellt; an anderen Stellen gelingt es, hie und da auch die allmähliche Aushöhlung dieses Zellstranges zt beobachten; es gehen dann von dem einen Gefäss zwei feine parallele Linien aus, die nach kurzem Verlauf wieder zu einem soliden Gebilde verschmelzen; das Lumen derartiger in 
Entwickelung begriffener Gefässe ist natürlich noch sehr eng, so dass nur in dem gewöhnlich trichterartig erweiterten Anfangstheil zellige Elemente Eingang finden. Weit häufiger und leichter za constatiren ist die vollendete Schlauchbildung, die im weiteren Verlauf der Entwickelung des Gefässes zur Abgrenzung und Differenzirung einzelner Zellen führt. Es geht aus diesen Beobachtungen hervor, dass die Gefässneubildung in der Hauptsache auf dem Wege der Sprossung erfolgt ist, und zwar unter Proliferation and Wucherung präexistenter Endothelzellen, die sich, wie aus mehreren Präparaten mit voller Sicherheit erhellt, auf dem Wege der indirekten Segmentirung zu vollziehen scheint.*) Ausser der in der Umgebung von Gefässen auftretenden Bindegewebsneubildung finden sich noch vereinzelte Anhäufungen von Bindegewebszellen, deren Entstehung offenbar im Hinblick auf ihre isolirte Lage, ihre Gefässlosigkeit auf eine Proliferation inselformiger Reste fixer Hornhantkorper zurückzuführen ist. - Hervorzuheben ist noch der Pigmentreichthum der Geschwürsmasse und der angrenzenden Theile des Hornhautparenchyms, theils innerhalb der Eiterzellen und fixen Bindegewebskörper, theils frei zwischen ihnen; in den Saftspalten und den fädigen Aussehwitzungen liegen in wechselnder Menge braune bis braunschwarze Pigmentpartikelchen eingestreut, die zum Theil vollkommen rund, zum Theil kurzstäbchenartig gestaltet sind; ihre Anordnung und Verbreitung ist dabei eine völlig regellose und atypische. Es entstammen diese Pigmentkörner offenbar den Iriszellen, und zwar sowohl den Bindegewebszellen wie den epithelialen Gebilden der Pars retinalis; aus diesen sind sie, anseheinend in Folge der entzündlichen Auflockerung der protoplasmatischen Zellsubstanz, in einen labileren Zustand übergeführt, ausgetreten und in den Saftstrom gelangt, uberall hin verschleppt worden und theils frei in den

*) siehe Fig. III. 
Gewebsspalten deponirt, theils auch wiederum von Eiterzellen und Bindegewebskörpern aufgenommen worden. Dass der grössere Theil dieses Pigmentes präformirt gewesen und aus pigmenthaltigen Zellen nur frei geworden ist, geht aus der Beobachtung zahlreicher in der Regel kreisförmig umschriebener pigmentarmer Stellen in dem Irisgewebe, und zwar vor Allem der Pars retinalis mit grosser Wahrscheinlichkeit hervor. Immerhin darf auch eine echte Pigmentneoplasie nicht gänzlich von der Hand gewiesen werden, da die lebhaften Proliferationserscheinungen die gesteigerte formative Energie der betreffenden Zellen deatlich bekunden und eine Aeusserung der erhöhten formativen Zellthätikeit in dieser Richtung (durch Pigmentneubildung) a priori zugegeben werden muss.

Dies sind im Wesentlichen die Ergebnisse der Untersuchung der parietalen Gesehwürsparthien und der von ihnen entwickelten im Geschwür liegenden Gewebeformen; die Basis des Ulcerationsdefektes füllt die prolabirte Iris aus und wird daher der Geschwürsgrund erst bei der Beschreibung der Irisveränderung eingehende Erwähnung finden. Die hintere Begrenzung des Hornhautparenchyms, die Membrana Descemeti, zeigt in ihren änsseren zwei Dritteln ausser eỉner mässigen trüben Schwellung îhres Encothelüberzuges keinerlei Veränderungen. Dagegen sind beide Gebilde, sowohl die Cuticularschicht, wie auch die Endothelhant, in der Mitte eingerissen und ihre Ränder, nach dem Hornhautepithel zu, bis zur vorderen Hälfte der Substantia propria umgeschlagen; die Descemet'sche Membran grenzt dabei, unter ausgesprochener Kräuselung nach vorn, das noch erhaltene Hornhautparenchym gegen das Gesehwür hin ab. Diese bemerkenswerthe Lagerung der Membran ist offenbar dadurch zu Stande gekommen, dass sich zunächst in Folge der trichterförmig von dem Epithel aus in die Tiefe dringenden eiterigen Einschmelzung des Hornhantbindegewebes ein Hydrocele der Descemet'schen Membran entwickelt hat; 
diese ist in Folge äusserer mechanscher Insulte und der gleichzeitigen Erhöhung des intraocularen Druckes geborsten und bei dem Ausströmen des Kammerwassers sind die beiden Membranen in der Ausdehnung des BindegewebsDefektes nach aussen umgeschlagen worden; aus dieser Umknickung des inneren Theiles und der wellenförmigen, den Einsenkungen der Substantia propria corneae sich anschmiegenden Anordnung der hinteren Basalmembran geht mit voller Sicherheit hervor, dass eine wirkliche Defektbildung in der Descemet'schen Membran nicht stattgefunden hat. Die Erklärung für diese hochgradige Resistenz ist in der Entwickelung des Organes zu suchen, aus welcher der Charakter einer Cuticularbildung und ihre völlige Gleichwerthigkeit mit den inneren Schichten dex Linsenkapsel mit Sicherheit hervorgeht; die Membrana Descemeti ist genetisch dem Uvealtractus zugehörig, da sie ihre Entstehung den ihr nach innen anliegenden Endothelzellen verdankt. - An dem nach vorn umgeschlagenen und in das Dleus hineinragenden Theil der Membran sind die Endothelien abgestossen und in dem eiterigen Secrct des Geschwürs einer völligen Zerstörung anheimgefallen. Durch die beschriebene Umfaltung der Descemet'schen Membran nach vorn und ihr Verhalten zu den Rändern des Hornhaut-Defectes wird die das Geschwür ausfüllende Gewebsmasse in der Tiefe scharf gegen den Rest des Hornhautbindegewebes abgegrenzt, so dass die ganze Geschwürsmasse genetisch streng genommen zwei verschiedenen Organtheilen entstammt: die oberflächliche Parthie deIn Hornhautbindegewebe und dem Gefässkranz am Limbus, die tiefere der prolabirten Iris, welche den durch den umgebogenen Theil der Descemet'schen Membran begrenzten Raum ausfüllt. In ihrer Zusammensetzung entspricht die von der Iris ausgehende Geschwürsmasse der des genaueren beschriebenen, von Hornhautparenchym entwickelten sowohl bezüglich der sie zusammensetzenden Elemente, wie auch bezüglich deren Anordnung. 
1. Dinkler.

Das die Iris nach vorn abgrenzende Endothel ist in Folge der eitrigen Fntzündung wahrscheinlich nekrotisirt und abgestossen; die vordere Irisfläche hat ihre leicht convexe, im Grossen und Ganzen glatte Oberfläche verloren und zahlreiche, von schmalen Bindegewebszellen begrenzte Gefässe dringen in das Geschwür ein und bilden durch zahlreiche Verzweigungen und Anastomosen den Grundstock für ein schwammiges, exsudatreiches Gewebe. Anch die hier in Frage kommende Gefässneubildung scheint sich anf dem Wege der Sprossung zu vollziehen; innerhalb der Gefässe überwiegen relativ die weissen Blutkörper, ebenso wie in den perivasculären Räumen; die Fibrin-Ausscheidung tritt gänzlich gegenüber der zelligen Infiittration zurück und nimmt erst nach der Oberfläche hin etwas an Menge zu. Die Differenzen in der Weite der einzelnen Gefässe fallen hier noch mehr in's Auge als in den oberflächlichen, dem Hornhautbindegewebe entstammenden Lagen; während ihr histologisches Verhalten das Gepräge der rom Limbus corneae nengebildeten Gefässe wiederholt. Die mit ihren inneren zwei Dritteln völlig prolabirte Iris, deren vordere freie Fläche an einer umschriebeneren Stelle in der Höhe und auf dem Niveau des Hornhautepithels anzutreffen ist, zeigt zunächst ausser der erwähnten Desquamation der vorderen Endothelhaut eine beträchtliche Volumenzunahme in ihrem Hôhendurchmesser und zwar übersteigt dieselbe an dem Pupillarrande das Doppelte der normalen Grösse. Die ganze Configuration der Regenbogenhaut zeigt sich ferner entsprechend der veränderten Topographie des Organes deformirt und von einem in einer Ebene gelegenen Diaphragma, wie es normal der Fall ist, kann nicht mehr die Rede sein. Die makroskopisch schon hervortretende diffuse Verdickung der Iris wird ausser einer nicht unbeträchtlichen Hyperplasie der fixen Bindegewebskörper und Gefässe bauptsächlich durch eine kleinzellige Infiltration bedingt, welche in der Pars uvealis nach Art kleinster 
multipler Abscesse zur Beobachtung kommt. Besonders ergriffen von dieser Zelleninvasion ist die vordere Grenzsehicht, deren charakteristische Elemente: die spindelförmigen Zellen weit auseinandergedrängt sich zwischen den zablreichen Rund- resp. Eiterzellenanhäufungen in reticulär angeordneten Zügen vertheilen. Diese Bindegewebskörper des Irisstromas zeigen zahlreiche Theilungsworgänge, die unter dem Typus der indirekten Segmentirung sich vollziehend, lebhaft für die Intensität der regenerativen Vorgänge sprechen. Die Muskellage des Sphincter pupillae ist im Ganzen durch die starke, zellige Infiltration verdeckt und nur an wenigen Stellen sind einzelne erhaltene Bündel nachweisbar. - Eine deutliche Grenze zwischen der Pars uvealis und Retinalis, wie sie normaliter die hintere Grenzlamelle bildet, ist nicht vorhanden; an zahlreichen Stellen setzen sich die kleinzelligen Infiltrationen direkt von dem einen in den anderen Theil fort. An dem retinalen Theile treten ferner vereinzelt kleine Verdickungen auf, die nach Art miliarer Abscesse zwischen vorderem und hinteren Blatt sich etablirt haben und aus dichtgedrängten Eiterzellen zusammengesetzt erscheinen. - Nach dieser Beschreibung bistologischer Veränderungen, wie sie sich an dem Hornhautbindegewebe und der Regenbogenhaut als den vorzugsweise von der Ulceration in Mitleidenschaft gezogenen Organtheilen vollzogen haben, erubrigt noch, auf das Verhalten der Neisser'schen Diplokokken zu diesen Geweben näher einzugehen und ist im Hinblick auf die Angaben E. Bumm's die Spannung wohl erkiärlich, mit welcher man dem Resultat der Untersuchung in dieser Hinsicht entgegensieht. Bei eingehendem Studium aller Präparate lässt sich zunächst constatiren, dass Tripperkokken thatsächlich in den genannten Organen vorkommen und sogar eine diffuse Verbreitung gefunden haben. Es finden sich nämlich die Kokken nicht nur in der aus Exsudat und Gefässen bestehenden Geschwürsmasse, sondern auch in der Substantia propria corneae und 
der Iris and zwar liegen sie in der Geschwürsmasse theils in dem Protoplasma der Eiterzellen, theils frei zwischen Bindegewebszellen und Gefâssen und in den Bälkchen der fibrinősen Aussehwitzungen; in letzteren sind sie in Haufen von 10 und mehr Paaren reihenweise angeordnet; zwischen den Eiterzellen und Bindegewebskörpern erscheinen sie in den gleichen Verbänden verstreut. Thre Zahl ist dabei sehr wechselnd; während man in manchen Theilen eine gewisse Mühe aufwenden muss, um uberzeugende Bilder zu bekommen, gelingt es an anderen schon beim ersten Versuch, grössere Züge einzustellen. In den Eiterzellen liegen sie in der bekannten Weise im Protoplasma verstreut, bisweilen in solcher Menge, dass Zelle und Kokken zu einem intensir gefärbten maulbeerartig gefurchten Klumpen verschmolzen sind. Weiterhin lässt sich mit Sicherheit constatiren, dass. abgesehen von den rein culturähnlich verbreiteten Kokkenhaufen der Epithel- und Geschwürs-Oberfläche die Vertheilung der Mikroorganismen in den einzelnen Tiefenlagen eine gleichmässige ist und scheinbar nicht durch die grössere Entfernung von der der Luft direkt ausgesetzten Oberflache nachtheilig beeinflusst wird. In dem erbaltenen Hornhautparenchym, in den Eiterzellen seiner Lakunen, Saftspalten und perivasculären Räumen sind die Kokken nur an der Grenze gegen das Uleus in grösserer Zahl nachweisbar; dagegen sind der weniger veränderte Theil der Substantia propria ebenso wie die in derselben liegenden Eiterzellenhaufen frei von Kokken und je weiter man sich in dem lamellären Parenchym der Cornea von dem Geschwürsrand entfernt, um so sicherer fallt die Untersuchung auf Kokken negativ aus. - Ganz anders dagegen verhält sich die Iris zur Ansiedlung der Trippermikroben; nicht nur an der Oberfläche, sondern auch auf dem ganzen Durchschnitt sind die Pilze in grosser Menge nachzuweisen, und zwar liegen sie immer wieder in der schon mehrfach beschriebenen 
Weise intra- und intercellulär*); dabei gelingt es, an einzelnen Stellen genauer zu beobachten, wie ihre Verbreitung und ihr Vordringen in die Tiefe erfolgt ist; man findet nämlich an den betreffenden Stellen der Oberfäche der Iris plattenförmige mehrschichtige Anhäufungen von Kokken, von denen aus, wenn auch nicht in völlig continuirlichem Zuge, die auf der Invasion betretenen Bahnen direkt bis zur Pigmentschicht und durch dieselbe hindureh bis in das die hintere Kammer erfüllende Exsudat sich verfolgen lassen. In den Gefässen sind die Kokken nirgends nachzuweisen; bisweilen wird dies wohl vorgetäuscht, bei genauerem Zusehen liegen sie aber doch zwischen den dem Perithel anliegenden Bindegewebszellen. - Diese Beobachtungen über die Verbreitung der Kokken in der Cornea und Iris ergeben so augenfällige Differenzen, dass es nöthig erscheint, mit einigen Worten auf die Erklärung derselben einzugehen. Jedenfalls spielt der wesentlich verschiedene Bau beider Organtheile wie auch die hervortretende Ungleichheit der Intensität der entzündlichen Reaction derselben in der Beantwortung dieser Frage eine Hauptrolle; denn offenbar sind bei den Entwickelungsbedingungen für die Tripperkokken, wie aus den Züchtungsversuchen Bumm's hervorgeht, nicht nur die Anwesenheit grôsserer Mengen von Nährsubstanzen, sondern vor allem auch deren häufiger Ersatz und Wechsel, wie er durch die reiche Vascularisation und beträchtliche Auflockerung eines Gewebes, wie der Iris, wohl gewährleistet werden kann, von hoher Bedeutung. Es ist daher aus den ungünstigen Circulationsbedingungen und dem starren Gewebsgefüge der Cornea leicht zu entnehmen, wesshalb dieselbe mit der aus einem reichen Netzwerk weiter Gefässschlingen und Saftspalten und aus einem stark gelockertem, reticulirtem Bindegewebe aufgebauten Iris in

*) siehe Fig. IV. 
der Bewirthung resp. Ernährung eines in jeder Beziehung so anspruchsvollen und andererseits so fragilen Parasiten wie des Tripperkokkus nicht erfolgreich concurriren kann. Mit den Veränderungen der Iris stehen in innigster Beziehung und directem genetischem Zusammenhang diejenigen zweier anderer Gebilde, nämlich: der vorderen und hinteren Augenkammer. Durch den Prolapsus iridis und die consecutive Verschmelzung derselben mit der Hornhaut ist die vordere Kammer aufgehoben oder wenigstens ad minimum reducirt, während die hintere eine beträchtliche Volumenvergrösserung erfahren hat. Da die Linse nur wenig nach vorn verschoben ist, so zeigt sich schon makroskopisch eine über $1^{1 / 2} \mathrm{~mm}$ tiefe Spalte zwischen Cornea resp. Iris and Linsenkapsel: die hintere Kammer eingefügt; ausgefullt ist dieselbe von einem theils fibrinösen, theils zelligen Exsudat, in dessen ganzer Ausdehnung Tripperkokken intra- und extracellulär nachweisbar sind; sicher trifft man die Kokken in den kleinen Eiterzellenhaufen, welche nach Art kleinster Abscesse in das Exsudat eingelagert sind, und ganz besonders häufig noch in den der vorderen Linsenkapsel aufliegenden Eiterkörpern; auf letzterer haben sich nämlich die Eiterzellen und Kokken wie auf dem Boden einer sedimentirenden Flüssigkeit in dichten Reihen abgelagert. - An der Linse selbst sind aus einer trüben Schwellung der Kapselepithelien keine bemerkenswerthen Veränderungen $\mathrm{zu}$ constatiren. Dagegen ist der Ciliarkörper, wie aus der kleinzelligen Infiltration und der Schwellung der einzelnen Fortsätze hervorgeht, in den entzündlichen Process mit hineingezogen und ist vielleicht das zwischen resp. vor und hinter den feinen Glaslamellen der Zonula Zinnii liegende zellige Exsudat zum Theil als das Produkt dieser Entzundung des Corpus ciliare anzusehen. Obwohl nähere Angaben über dieses Organ und seine Fortsătze, sowie über den Glaskörper, die Chorioides und Retina nicht möglich sind, da bei der Härtang des 
Präparates diese Theile nicht in toto mit conservirt wurden, so kann man doch aus dem Vorkommen von Eiterzellen hinter der Linsenkapsel und dem Strahlenbändehen mit vollem Reeht den Schluss ziehen, dass auch eine eiterige Hyalitis vorhanden gewesen ist; wie weit diese allerdings papillarwärts vorgeschritten und in wie weit Netz- und Aderhaut in den Process einbezogen waren, daruber lasst sich kein begründetes Urtheil gewinnen. - Eigenthümlich und besonders hervorzuheben ist, dass auch in diesem eiterigen Exsudat, welches inner- und ausserhalb der Kuhnt'sehen Räume sich ausbreitend, auf der einen Seite besonders entwickelt ist, - vielleicht entspricht gerade diese der intra vitam tiefst gelegenen Parthie der Camerae posteriores, - intra- und extracellulär gelegen typische Tripperkokken in reicher Menge zu beabachten sind.*) - Ferner hat ebenso, wie in den früher beschriebenen Theilen der Hornhaut und der Geschwürsmasse, eine beträchtiche Pigmenteinschwemmung in sonst pigmentfreie Theile, wie den Glaskörper und die Exsudatelemente stattgefunden und kann auch dieser Befund wohl als Stütze für die früher gemachte Supposition einer pathologisch gesteigerten Labilität des Pigmentes bei entzündlichen Affectionen pigmentirter Gewebe verwendet werden; bezüglich der Lage und Vertheilung dieses retrolenticulär vorhandenen Farbstoffes sowie bezüglich der Form, in weleher er auftritt, genügt es, auf die Beschreibung des einschlägigen Befundes in der Cornea und Geschwürsmasse hinzuweisen. - Soviel über das der kleinen Bertha Franz entnommene Präparat!

Die Beschreibung des zweiten Falles wird unbeschadet der Genauigkeit des Resultates weit kürzer ausfallen können, da voraussichtlich bei der Gleichheit des ursächlichen Agens eine Anzahl der bereits geschilderten Veränderungen sich ebenso oder mit unwesentlichen Abweichungen wiederholen

*) siehe Fig. V. 
dürften. - Makroskopisch gewährt dieses Präparat eine im Wesentlichen unveränderte anatomische Lagerung seiner einzelnen Theile; die Cornea ist anscheinend in toto erhalten und lässt ausser einer mässigen Abflachung der normalen Wölbung eine leicht unregelmässige Oberfläche erKennen; bei der Färbung zeichnet sich ein etwas excentrisch gelegener Theil durch eine auffallend intensive Imprägnation mit Farbstoffen aus, und zwar erstreckt derselbe sich, wenn auch ganz umschrieben, durch den Durchmesser der ganzen Cornea bindurch bis in die vordere Kammer. Die letztere ist etwas abgeflacht in Folge der erwänten Abnahme der Hornhautkrümmung und enthält eine feine durchscheinende, nur an der Grenze gegen die Cornea hin deutlich sich färbende Substanz. Die Iris ist als Diaphragma oculi in seiner normalen Lage erhalten und zeigt selbst keine mit blossem Auge wahrnehmbaren Veränderungen; die Pupille ist frei und von mittlerer Weite. - Bei der mikroskopischen Untersuchung lässt sich leicht constatiren, dass das Hornhautepithel und die oberflächlichen Schichten des Bindegewebes etwa innerhalb der inneren zwei Drittel der Cornea feblen; nach aussen von diesem Defect ist das Epithel wohl vorhanden, zeigt aber wesentliche Veränderungen seiner Structur; stellenweise ist nämlich der Durehmesser auf 3-4 Zellenlagen reducirt, wăhrend an anderen Theilen, besonders an der Grenze gegen die Conjunctiva bulbi hin zapfenförmige Wucherungen zu einer betrachtlichen Volumenzunahme des Epithellagers geführt haben. Letztere sind anatomisch auf eine Proliferation der Zellen, und zwar der basalen Schichten des Stratum epitheliale zurückzufubren; die dabei auftretenden Kernfiguren zeigen den normalen, der indirekten Segmentirung eigenthümlichen Typus, ohne dass eine der früher beschriebenen ähnliche Varietät der Knäuelfigur zur Beobachtung gelangt. - Den abnormen Vorgängen im Protoplasma und im Kern der Zellen entsprechen ferner weitgehende Aenderungen, die 
sich an der äusseren Form und Umgrenzung der Epithelien vollzogen haben; von einer regelmässigen geschichteter Anordnung morphologisch rom Cylinder- bis zum Plattenepithel sich abstufender, zu einer gleichmässigen Membran verbundener Zellgebilde kann kaum gesprochen werden, denn an der einen Stelle herrscht dieser, an der anderen jener Zelltypus ausschliesslich vor; man trifft im Grossen und Ganzen eigentlich nur zwei der Form nach verschiedene Zellarten: kubische und platte Zellen, deren jemaliges Ueberwiegen an den einzelnen Theilen erklärlieher Weise zo ganz differenten Bildern führt. - Es ist weiterhin a priori schon anzunehmen, dass bei einer so beträchtlichen morphologischen Aenderung der einzelnen Epithelelemente auch eine Aenderung des intercellularen Epithelgefüges eingetreten sein muss; dasselbe, welches normal als feinstes Kittleistennetzwerk nur mit Hülfe besonderer Reagentien nachweisbar ist, ist theilweise in Folge der Entzündungsvorgänge gänzlich aufgehoben und dadurch die Zellverbindung so gelockert, dass eine plastische wie cellulare Ausschwitzung in die interepithelialen Spalträume erfolgt ist; die dabei eingedrungenen Eiterzellen haben sich mehrfach in solcher Menge angehäuft, dass die Epithelzellen gänzlich verdeckt werden. An anderen Stellen wiederum ist das Intercellulargefüge derartig erhöht und gefestigt, dass die einzelnen Zellindividuen zu einer gleichmässigen hyalinen Masse, die nur durch die eingelagerten streifenförmig gestalteten Kerne unterbrochen wird, verschmolzen erscheinen. - Die hintere Epithelgrenze ist, abgesehen von der ausgeprägten Papillenbildung, auch in den übrigen Parthieen unregelmässig: es sind sogar einzelne Epithelien von dem Stratum abgesprengt und nach der Tiefe dislocirt, ein Befund, dessen Genese durch die auffallende Weite der interepithelialen Saftspalten und beträchtliche Lockerung des Intercellulargefüges der betreffenden Stellen genügend erläutert wird. Dass bei der hervortretenden Unregelmässigv. Graefe's Arohiv fir Ophthalmologie, XXXIV. 3 . 
keit der Epithelgrenze auch die anliegende Basalmembran gewisse Aenderungen, sei es in Form einfacher Ausbuchtung and Faltenbildung, sei es in Form von Usurirung und Defektbildung, erfahren hat, ist gewiss als selbstverständlich vorauszusetzen, Nach der wiederholten Untersuchung zahlreicher Schnitte zu urtheilen, ist sie in der ganzen Ausdehnung der Cornea geschwunden und selbst unter den epitheltragenden Parthieen, wo man sie doch wenigstens stellenweise erhalten wähnen sollte, trifft man statt dessen eine aus Leukocythen resp. Eiterkörpern und spärlichen Bindegewebszellen bestehende Gewebsmasse; gerade die vorwiegende Zusammensetzung dieser subepithelial gelegenen Gewebetheile aus Biterzellen deutet zugleich die Art und Weise an, auf welche nach Analogie des erst beschriebenen Falles die Zerstörung der bindegewebigen Basalınembran höchst wahrscheinlich erfolgt ist, nämlich: Vermittelst einer eiterigen Einschmelzung; dass dabei der Schwund ein totaler ist, erklärt sich aus der diffusen unter dem Epithel ebenso, wie an dem Geschwürsrand ausgeprägten eiterigen Infiltration, die im Grossen und Ganzen mehr destructive als Regeneration anregende Bahnen zu verfolgen scheint. - Das Hornhautbindegewebe hat durch die nach der Tiefe vordringende Ulceration einen im Wesentlichen flächenhaften Defect erfahren und nur an einer umsehriebenen excentrisch gelegenen Stelle ist eine trichterförmige Einsenkung mit Perforation nach der vorderen Kammer eingetreten. Der superficielle Substanzverlust ist, wie schon Eingangs bemerkt, in der Flächenausdehnung sehr beträshtlich und zeigt einen zackigen, wie angenagten Rand; im Wesentlichen wird er durch eine mehrfache Eiterzellenschicht abgegrenzt, welche, nur durch strunkartige, sagittal gerichtete Lamellenrudimente stellenweise unterbrochen, direkt in die den trichterformigen Perforationscanal ausfüllende Gewebsmasse übergeht. Letztere enthält nur wenige Gefãsse und geringe Bindegewebsmengen, ihren Hauptbestandtheil bilden Eiterzellen und in 
zweiter Linie Faserstoffausscheidungen. In den den Geschwürstrichter umgrenzenden Theilen des Hornhautparenchyms ist der lamelläre Charakter der Bindegewebselemente erhalten, nur die Richtung der Lamellen hat auf eine kurze Strecke eine Aenderung erfahren, insofern, als dieselben durch die eiterige Entzündung erweicht, mit dem Bersten der Descemet'schen Membran und dem Ausströmen des Kammerwassers nach vorn gespült worden sind und an der Stelle, wo die Consistenz wieder der normalen Höhe nahekommt, fast rechtwinklig eingeknickt erscheinen. Sowohl die frontal verlaufenden, wie diese umgebogenen Lamellen zeigen gewisse Veränderungen ilhrer feineren Structur und ihres Volumens und zwar bestelen dieselben bei den peripher gelegenen Bindegewebsfascikeln in einer deutlichen Aufquellung und Verwischung ihrer fibrillären Anordnung, während an den centralen Theilen ausser diesen nutritiven Störungen noch eine stufenweise sich steigernde Defectbildung zu constatiren ist; dieselbe ist offenbar unter der Dinwirkung der eitrigen Entzündungen in der Weise erfolgt, dass die Eiterzellen zunächst circumscript eine unregelmässige Erweiterung der Saftlakunen und dann auf ihrer Wanderung durch die Saftspalten festgehalten auch hier eine Usurirung der fibrillären Substanz einleiteten, wie aus den, wie Guss und Form sich völlig gleichenden Zellgebilden einerseits und Substanzdefekten andererseits mit Sicherheit hervorgeht. Die Zeichnung, welche aus der auffallenden Verquellung and Homogenisirung der fibrillären Substanz, sowie aus den verschieden gestalteten, mit Zellen erfüllten Resorptionslücken resultirt, ist vielfach eine so eigenthümliche, dass sie unwillkürlich an das Structurbild des hyalinen Knorpels erinnert: in gewissen Abständen sind vereinzelte, mit granulirtem Protoplasma und mehrfach getheiltem Kern versehene Zellen, deren scharf gezeichnete Membran als ein den Knorpelkapseln homologes Gebilde imponiren kann, in eine fast völlig hyaline, nur wenige Spalträume bergende Grund- 
substanz eingefügt. - Die Gefässneubildung, welche nur gering ist, erfolgt offenbar von den conjunctivalen Randsehlingen aus in Form fast durchgehends diffus erweiterter Capillaren, deren abnormer Durchmesser anscheinend dem Wegfall des Aussendruckes in Folge der entzündlichen Auflockerung des lamellären Gefüges seine Entwickelung verdankt; die kleinzellige perivasculäre Infiltration ist dabei eine so beträchtliche, dass äber die Art und Weise der Gefüssneubildung - ob sie vielleicht auch durch Sprossenbildung erfolgt - sichere Angaben nicht gemacht werden können; die Endothelzellen zeigen eine ausgeprägte Granulirung und deutlich protoplaswatischen Inhalt. - Die fixen Bindegewebskörper des lamellären Hornhauttheiles zeigen ausser einer trüben Schwellung und Vaccuolenbildung keine Aenderungen; dagegen findet man unter den in der Geschwürsmasse verstreuten Bindegewebszellen zahlreiche in Kerntheilung begriffen. - In einzelnen Parthicen lässt sich ferner eine mässige Pigmenteinschwemmung nachweisen und zwar liegen die kurzstäbchenartig geformten Pigmentkörner theils frei in den Saftspalten, theils interund intracellulär in dem eiterigen Exsudat; es vermag auch diese Beobachtung für die fruher ausgesprochene Annahme, dass mit den entzündlichen Processen an der Cornea, Iris und Corpus ciliare zugleich eine gesteigerte Labilität des Pigmentes einhergeht, zu zengen. Zwischen dem Hornhautbindegewebe und der Descemet'schen Membran finden sich mehrfach Hohlräume, deren einige nur mit einer granulirten serumartigen Substanz erfüllt sind, während die Mehrzahl nach Art miliarer Abscesse aus einer Conglomeration zahlreicher Eiterzellen besteht. Die Descemet'sche Membran selhst lässt in der Tiefe des Gesehwürs einen diesem entsprechenden, etwas excentrisch gelegenen Riss von mässiger Ausdehnung erkennen, dessen Ränder vermöge der der Membran eigenthümlichen Eigensehaft sich in isolirtem $\mathrm{Zu-}$ stande nach vorn einzurollen, und in Folge der vis a tergo 
des ausströmenden Kammerwassers unter geringer Faltung nach vorn umgeschlagen sind. Die Endothelschicht, deren einzelne Zellelemente eine trübe Schwellung und Vaccuolenbildung erfahren haben und mehrfach durch eingedrungene Eiterzellen völlig verdeckt werden, liegt stellenweise der Descemet'schen Membran an, theilweise aber ist sie unter beträchtlicher Faltenbildung auf eine grössere Strecke abgehoben, denn man trifft in dem eiterigen Exsudat der vorderen Kammer an mehreren Stellen Complexe von epithelioiden Zellen, deren Entstehung bei ihrer isolirten Lage und grösseren Entfernung von ähnlichen Gebilden nur durch eine die Endothelmembranfalten tangential treffende Schnittführung erklärt werden kann. Dass diese Deutung auch der Wirklichkeit entspricht, wird des Weiteren dureh die charakteristische Form der einzelnen Zellen und ihre intercellulare Verbindung bestätigt. - Die vordere Kammer zeigt keine beträchtliche Verringerung des Tiefendurchmessers; ausgefüllt ist dieselbe mit einem theils plastischen fibrinösen, theils zelligen Exsudat, dessen Zusammensetzung bezüglich der Menge der Eiterzellen gewisse Schwankungen erkennen lässt; am meisten überwiegen die Eiterzellen in der Nahe der Hornhaut. - Die Iris zeigt neben einer mit geringer Intumescenz verlaufenden serösen Durehfeuchtung eine mittlere kleinzellige Infiltration des ganzen Parenchyms; die geringgradig erweiterten Blutgefässe enthalten grosse Mengen weisser Blutzellen; die specifischen Iriselemente: die Bindegewebszellen lassen ausser häufigeren Mitosen keine Veränderungen erkennen. Die hintere Kammer ist frei von jedem Exsudat, ebenso ist die Betheiligung der vorderen Parthieen des Corpus eiliare nur gering. Wie aus dieser kurzen Skizzirung der histologischen Veränderungen leicht zu ersehen ist, zeigt die entzündliche Reaction der Gewebe gegenüber dem erst beschriebenen Fall einen geradezu torpiden Charakter mit vorwiegend destruktiven, geringen regenerativen Folgeerscheinungen. - In ähn- 
licher Weise negativ ist auch gegenüber dem ersten Fall das Resultat der bakteriologischen Untersuchung des vorliegenden Präparates; man findet nämlich die Kokken in grosseren Mengen nur stellenweise auf und zwischen den Epithelien in Form rasenförmiger Auflagerungen oder in reihenformigen Zügen; in viel geringerer Zahl liegen sie in den oberen Schichten des Bindegewebsdefectes, und zwar in typischer Weise intra- wie intercellulär. Tiefer als etwa in der sechsten bis achten Eiterzellenschicht des Geschwürsrandes werden sie nach dem Hornhautparenchym zu nicht beobachtet und auffallender Weise sind sie auch in dem trichterformigen Perforationscanal und dessen eiterigem Exsudat ebenso wenig wie in dem Hypopyon und der Iris zu finden.

Bei einem Rückblick auf das Gesammtresultat der vorliegenden Untersuchungen treten sowohl in histologiseher wie mykologischer Beziehung, wie bereits angedeutet, gewisse Differenzen in den beiden Fällen hervor, auf deren Erklärung noch mit einigen Worten einzugehen erübrigt. Nur bei einem oberflächlichen Vergleich kann es den Anschein erwecken, als seien tiefgehende Unterschiede in dem Krankheitsbild beider Fälle und seiver anatomischen Grundlage vorhanden; bei eingehenderem Studium ergiebt es sich bald, dass es sich offenbar nur um graduelle Unterschiede handelt, denn beide Falle haben das Wesentliche des Processes, eine primäre eiterige Zerstörung der Hornhaut mit consecutiven Regenerationserscheinungen, gemeinsam, nur ist in dem ersten Fall die Affection überhaupt weiter gediehen als in dem zweiten und vor allem sind bei dem Fall "Bertha Franz" die regenerativen Erscheinungen in Form von Epithelwucherung, Gefässneubildung, Bindegewebszellenproliferation etc. so auffallend, dass sie die geringen neoplastischen Processe, wie sie in dem Falle "Eekebrecht" an den gleichen Gewebetheilen zur Beobachtung kommen, weit in den Schatten stellen. Diese 
graduellen Differenzen sind vielleicht zum Theil von der geringen, beziehentlich hochgradigen Virulenz des Infectionsstoffes, zum Theil wohl auch dem verschiedenen Alter der beiden Patienten, sowie ganz besonders der ungleichen Dauer des Processes herzuleiten. Dass die Virulenz eines und desselben Mikroorganismus unter dem steten Wechsel seiner Lebensbedingungen grossen Schwankungen unterworfen ist, bedarf ebenso wenig wie die bekannte Verschiedenheit in der Empfänglichkeit einzelner Individuen für das gleiche organisirte Gift einer eingehenden Erörterung; dass ferner auch das Alter bei den einzelnen Infectionskrankheiten bezüglich der schliesslichen Reaction des befallenen Organismus resp. Organes von Bedeutung

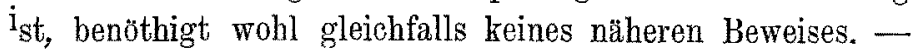
Ein weiterer Grund für die verschiedene Zahl der Tripperkokken in den beiden Fällen kann darin zu finden sein. dass diese Mikroorganismen, wie aus den Bumm'schen (1. c.) Züchtungsresultaten hervorgeht, bei ihrer Entwickelung bestimmte, ihr Wachsthum hemmende oder ganz aufhebende Substanzen abscheiden und dadurch einen bereits von ihnen bewachsenen Nährboden dauernd für eine gleiche zweite Inoculation steril zu machen vermögen. Vielleicht sind diese Substanzen, welche bei der hochgradigen Vascularisation des ersten Präparates anscheinend einer dauernden Abfuhr unterlagen, bei dem torpiden Charakter der Entzündung in dem Falle "Eckebrecht" für die geringe Menge der Tripperkokken von ursächlicher Bedeutung.

Gehen wir am Schlusse der kurzen Mittheilung der beiden Fälle noch einmal auf die von den Bumm'seben Angaben (l. c.) differenten Befunde ein, so glauben wir, gestützt auf die eingehende Prüfung zahlreicher Präparate, mit voller Sicherheit erwiesen zu haben, dass Tripperkokken im Plattenepithel der Cornea und ebenso in dem Bindegewebe derselben und der Iris unter der Einwirkung eines 
primären Bindehauttrippers zur Entwickelung und weiteren Verbreitung gelangen. Es laufen diese Ergebnisse den offenbar aprioristisch verallgemeinerten Thesen $\mathrm{Bumm}$ 's denn über Untersuchungen der Hornhautvereiterung nach Conjunctivaltripper ist in der Monographie mir nichts bekannt geworden (pag. 120) - so direct entgegen, dass es angezeigt erscheint, den Einwand, dass es sich nämlich in beiden Fällen nicht um Tripperkokken, sondern um irgend welche anderen Mikroorganismen gehandelt habe, selbst zu erheben und zu widerlegen. Als charakteristisehes Kennzeichen der in unseren Fällen beobachteten Kokken sind drei hervorzuheben: die Diplokokkengestalt, die Lage in dem Protaplasma der Biterzellèn und das Färbeverhalten. Was zunächst die Gestalt anbetrifft, so entsprechen die fraglichen Kokken völlig dem bekannten Diplokokkentypus, dessen Einzelheiten schon früher hinreichend Erwäbnung gefunden haben; es liegen stets zwei Kokkenhälften mit ihren leicht concaven Flächen einander gegenüber und bilden so ein einheitliches Kokkenexemplar; die Vermehrung derselben erfolgt durch eine senkrecht zum Längsdurchmesser jeder Kokkenhälfte eintretende Quertheilung - anscheinend genau in derselben Regelmässigkeit und Gesetzmässigkeit wie bei zelligen Gewebs-Gebilden wie aus den wechselnden Grössenverbältnissen und der. häufigen Anordnung der Kokken nach dem bekannten Tetrakokkus-Schema genügend hervorgeht. Zweitens ist das endocelluläre Vorkommen, welches eine specifische Eigenthümlichkeit der Tripperkokken zu sein scheint und für die differentielle Diagnose als aussehlaggebend anzusprechen ist, so häufig und zugleich so prägnant, dass über die Art der fraglichen Mikroben schon nach Durchmusterung eines einzigen Präparates kein Zweifel mehr herrschen kann; die Kokken liegen einzeln oder zu Tetrakokken vereint in dem Protoplasma der Zellen verstrent; bre wirklich intracelluläre Lage geht daraus mit voll- 
ster Sicherheit hervor, dass man bisweilen Kokken ganz peripher gelegen antrifft, welche von innen her die Zellmembran ausbuchten. - Berühren wir dabei die Frage, wem eigentlich die Initiative für die Einlagerung in das Zellprotoplasma zukommt, ob den Kokken oder den Eiterzellen, mit einigen Worten, so scheinen uns die Bumm'schen (l. e.) Bemerkungen, welche sich gegen die Aufnahme der Kokken in das Zellprotoplasma durch dessen eigene Thätigkeit richten, vorwiegend subjectiver Natur; denn ganz abgesehen von dem Misslingen des Versuches, diesen Vorgang künstlich zu erzeugen, kann ein vergleichsweiser Schluss, wie ihn Bumm aus dem Verhalten anderer Kokken gegenüber den Leukocyten zieht*), bei der in vieler Beziehung exceptionellen Stellung der Tripperkokken nur wenig überzeugende Kraft haben. Nach unserer Beobachtung liegt die von Seiten der Zellen ans erfolgende Aufnahme der Kokken in die Protoplasmasubstanz, ohne damit den Process direct als phagocytotischen hinstellen zu wollen, sehr nahe und wird durch die Beobachtung von Tripperkokken binter der Linse resp. Zonula Zinnii gestützt, da sich an den betreffenden Präparaten weder im Ciliarkörper noch in dessen Fortsätzen in Zügen nach dem Glaskörper vordringende Kokkenhaufen, durch welche dieses Vorkommen hinter der Linsenkapsel erklärt würde, nachweisen liessen; es macht daher den Eindruek, als seien die Kokken vermittelst der Eigenbewegung der sie bergenden Zellgebilde in diese entlegenen Parthien transportirt worden. Ueberhaupt scheint die Propagation der Tripperkokken nach der Tiefe, abgesehen von der directen Fortwucherung, welche interepithelial wohl die typische ist, im Bindegewebe in der Weise zu erfolgen, dass kokkenhaltige Eiterzellen

*) Uebrigens werden die Staphylokokken anch „endocellulär“ beobachtet, allerdings in viel geringerer MLenge und auch weit seltener als die Tripperkokken. 
IV. Dinklex.

durch die Saftströmung oder irgend welche, nur zu vermuthende Wechselbeziehungen zwischen ihnen und dem Gewebe mit ihrer keineswegs indifferenten Last von der ursprünglichen Richtung abgelenkt und in einen entfernten noch kokkenfreien Theil des Organes verschlagen werden; im Verlauf der Theilung und Vermehrung der Kokken fallen die Zellen auseinander und es kommt zur Bildung eines frei intercellular gelegenen Kokkenhäufchens, von dem aus in der eben angedeuteten Weise weitere Verschleppungen erfolgen können. - In der Voraussetzung, dass, wie in unseren beiden Fallen, die eben beschriebenen Kennzeichen: die Diplokokkengestalt und die endocelluläre Lage zweifellos festgestellt sind, kann schliesslich noch als weiterer Beweis für die Identität einer derartigen Kokkenart mit Tripperkokken das Färbeverhalten derselben herangezogen werden. - Tripperkokken im Gewebe zu färben macht Anfangs gewisse Schwierigkeiten, da sie den Farbstoff bei der Entfärbung des Gewebes nicht genügend festhalten und man, um diesem Uebelstande möglichst abzuhelfen, die stärkst färbenden Anilinfarben, wie Methylund Gentianaviolett in Anilinwasserlösung zu benutzen gezwungen ist. Die ersten Präparate habe ich genau nach der Bumm'schen (1. c.) Vorschrift angefertigt und dabei klare und befriedigende Bilder erhalten; da jedoch die ausschliessliche Alkoholentfärbung der Präparate wegen der für den Anfänger schwer zu erreichenden Grenze zu unsicher und zu zeitranbend und ausserdem noch die Gewebedifferencirung (vorwaltende Kernfärbung) nicht besonders scharf ist, machte ich den Versuch, das ganze Verfahren mit Hülfe der Gram'schen Methode zu vexeinfachen. Das Resultat war jedoch, wie auch Bumm betont, negativ, denn Gewebe wie Kokken entfärbten sich nach 2-3 Minuten langem Verweilen in Lugol'scher Lösung $(1: 2: 300)$ bei der Auswaschung in Alkohol oder Anilinöl (Weigert, Fortschritte der Medicin 1887, Heft 8) 
gleichmässig. Wenn auch in dieser Richtung negativ, liess dies Ergebniss doch volle Sicherheit darüber gewinnen, dass keine anderen pyogenen Mikroorganismen - denn die Eiterkokken sind bekanntlich ein sehr dankbares Object für die Färbung nach der Gram'schen Methode - in den erkrankten Geweben vorhanden sind. - Aus weiteren Versuchen ging jedoch hervor, dass die Ausfällung des Farbstoffes bei nur einige Secunden währender Einwirkung der Jodjodkalilösung sich auf ein erwünschtes Maass reduciren lässt; die sich anschliessende Abspülung und Entwässerung in absolutem Alkohol ist in kurzer Zeit vollendet und die so behandelten Schnitte haben vor den nur mit Alkohol entfärbten den Vorzug der besseren Differencirung; das Protoplasma der Zellen und die Intercellularsubstanz haben den Farbstoff grösstentheils abgegeben, während die Tripperkokken und die Kerne intensiv blauviolett gefärbt erscheinen; makroskopisch können die Schnitte noch verhältnissmässig dunkel sein, ohne desswegen undeutliche Bilder zu geben. - Ebenso gelingt es mit Hülfe von kurzer Einwirkung einer Tropaeolin-Essigsäurelösung (C. Fränkel, Bakterienkunde p. 250) die Alkoholentfärbung abzukürzen. Ausser der Methylviolettund Gentianaviolett-Anilinwasserfärbung verdient noch eine bis jetzt weniger verwendete Färbemethode hervorgehoben za werden: die mit Löffler'schem Methylenblau (Mitth. aus dem kaiserl. Gesundheitsamt, Bd. II, p. 439). Diese Farblösung hat den grossen Vorzug, dass sie selbst bei längerer Einwirkung einmal nicht überfärbt und zweitens die Auswaschung des Farbstoffes bis zu einer guten Differenzirung nach kurzer Alkoholbehandlung ermöglicht; bezüglich des mikroskopischen Bildes übertrifft diese Färbung (besonders in Bezug auf das eiterige Exsudat in der vorderen und hinteren Augenkammer etc.) die vorher erwähnten Methoden, da die Kokken eine gesättigte tiefblane Färbung zeigen und gegenüber den hell- oder grünblauen Kern- 
theilen scharf contourirt hervortreten; besonders geeignet ist diese Methode der ,metachromatischen" Färbung zur genaueren Verfolgung des Theilungsvorganges der Kokken. Es kann demnach sowohl für Gewebe wie für Secretfärbung zum Nachweis von Tripperkokken die Anwendung der Löffler'schen Methylenblaulösung in folgender Form empfohlen werden:

a) Schnitte:

1. ca. 10 Minuten lange Färbung in der Löffler'schen Lösung;

2. Entwăsserung und Auswaschung des uberschüssigen Farbstoffes in Alkohol mit oder ohne vorherige kurze (!!) Einwirkung der oben genannten Essigsäurelosung;

3. Aufhellung in Cedernholzöl ete.

b) Deckglăschen mit fein ausgestrichenem secret:

1. $1-1^{1 / 2}$ Minuten währendes Färben in der Löfflerschen Lösung;

2. Abspülung in Wasser ete. - Untersuchung.

Es treffen sonach bei den in Rede stehenden Mikroorganismen sämmtliche Kennzeichen, welche Bumm (l. c.) selbst in seiner Monographie als charakteristisch für Tripperkokken hervorhebt, zusammen und glanbe ich ihre Identität mit den Tripperkokken nach jeder Richtung hin - soweit es überhaupt mit Hulfe des Mikroskopes ohne Culturversuche möglich ist - sicher gestellt zu haben. Toh hebe dabei nochmals folgende Punkte als entscheidend für die Deutung des bakteriologischen Befundes der beiden in Frage stehenden Fälle hervor: erstens das Bestehen eines durch den mikroskopischen Nachweis von Tripperkokken im Seeret und durch die klinisehe Beobachtung zweifellos constatirten Conjunctival-Trippers als Vorbedingung für die Hornhautvereiterung, zweitens die charakteristische, den im Secret gefundenen Mikro- 
organismen gleichende Form der Diplokokken, drittens ihr intracelluläres Vorkommen und schliesslich ihr Färbeverhalten. Für die Annahme einer Mischinfection durch Tripper- und Eiterkokken zugleich liegen keinerlei Anhaltepunkte vor, wohl aber sprechen gegen eine derartige Deutung des vorliegenden Processes erstens die absolute morphologische Gleichartigkeit der beobachteten Mikroorganismen - gleichviel, ob man sie zwischen den Epithelien oder in der Iris oder im Exsudat hinter dem Strahlenbändchen von diesem Gesichtspunkt aus der genanesten Prüfung unterwirft - und zweitens die einheitliche Entfärbung derselben bei Anwendung der Gram'schen Reaction; sicher sind in sämmtlichen Präparaten weder Streptokokken noch Staphylokokken nachzuweisen; die ersteren können wobl überhaupt bezüglich einer differentiellen Diagnose kaum Schwierigkeiten bereiten, da sie in der augenfälligen kettenartigen Aneinanderreibung ihrer einzelnen Zellindividuen ein so hervortretendes Kriterium besitzen, dass es selbst dem Anfänger. schwer fallen wird, sie zu übersehen oder zu verkennen; die. Staphylokokken zeigen hingegen schon eher eine Annäherung an die hier beschriebene Kokkenform, sind aber bei genauerem Vergleich ebenfalls wegen ihres abweichenden Verhaltens zum Gewebe, wegen ihrer exquisiten Kokkus-Gestalt und ihrer innerhalb weiterer Grenzen schwankenden Grössenverhältnisse mit Sicherheit auszuschliessen. Es handelt sich demnach in den beiden Fällen um eine Infection durch einen einheitlichen Mikroorganismus, dessen Gestalt und Verhalten gegenüber dem Gewebe und den gebräuchlichen Farbstoffen unter den bekannten Spaltpilzformen in jeder Beziehung dem der Neisser'sehen Tripperkokken entspricht.

Schliesslich wäre noch die Frage zu beantworten, welche Fälle von Conjunctivaltripper zu einer Hornhautvereiterung führen und worin das treibende Moment für diese schwere Complication der Erkrankung zu suchen ist. Anatomisch 
hat sich, wie vorauszusehen, an den beiden Präparaten kein Anhaltepunkt finden lassen; dagegen ist es klinisch genügend bekannt, dass Tripperconjunctiritiden mit crupösdiphtherischen Erscheinungen besonders häufig zu einer Hornhautvereiterung führen; es ist ferner sogar sehr wahrseheinlich, dass unvorsichtiges oder zu frühes Tonchiren der Bindehant mit Arg, nitric als ätiologisches Moment für das Eintreten einer Hornhautaffection beschuldigt werden muss. In beiden Fällen, bei diphtheroider Infiltration, sowie bei unzweckmässigem Touchiren (Persistenz der Eschara) scheint die hierdurch bedingte Rigidität und Rauhigkeit der Conjunctivaloberfläche auf rein mechanischem Wege, durch erhöhte Reibung der Lider an dem empfindlichen zarten Cornealepithel, die erste Veranlassung zur Hornhauterkrankung zu geben, denn nach einer derartigen traumatischen Epithelabschülferung sind den Mikroben Thür und Thor zur event. Invasion geöffnet. Es ist daher wohl berechtigt, diphtheroide Conjunctivaltripper im Beginn mit Eiswasserumschlägen und häufigen Sublimat-Borsăureausspülungen mehr exspectativ zu behandeln, bis das phyorrihoische Stadium mit seiner typischen Arg. nitric- und Eiswasserbehandlung eintritt, und zweitens alle frisch in Behandlung kommenden gering secernirenden Fälle zunächst mit einer schwachen Höllensteinlösung zu ätzen, um genügende Sicherheit bezüglich der langsamen oder schnellen $\mathrm{Ab}$ stossung der Eschara zu erlangen. 
Erklärung der Abbildungen.

Higur 1.

Hornhautepithel, (Hartn. Obj. 7, Oc.3.)

a in Theilung begriffene Zellen, der Knäuelfigur entsprechendes Stadium,

b Epithelien mit Stachelfortsätzen,

c interepitheliale Spalträume,

d subepitheliale Eiter- resp. Wanderzellen.

Figur 2.

Hornhautbindegewebe. (Hartn, homog. Imm. I. Oc. 3.)

a Vordere Basalmembran im gequollenen Zustand,

b Eiterzellen in dieselbe eindringend,

c Epithelzellen.

\section{Figur 3.}

Iris. (Hartn. Obj. 7, Oc. 3.)
a Kerntheilung einer Endothelzelle in der Iris,
b Pigmentkörnchen,
c Weisse Blutzellen,
d Bindegewebszellen der Tris.

\section{Figur 4.}

Gewebstheil aus der Mitte der Iris. (Hartn. homog. Imm. I, Oc. 3.)
a Iriszellen,
b weisse Blutkörper oder Eiterzellen,
c Capillargefässe,
d freie Tripperkokken,
e intracellnlär gelegene Tripperkokken. 
Figur 5.

Exsudat, hinter der Linse gelegen. (Hartn. homog. Imm. I. Oc. 3.)
a kokkenhaltige Eiterzellen,
b Biterzellen,
c Pigmentkörner.

Figur 6.

Hornhaut-Bindegewebe "Fall Eckebrecht”, (Hartn. Obj. 7, Oc. 3.)

a Eiterzellen,

b za einer homogenen Substanz verquollene Bindegewebslamellen der Hornhant. 
$\int^{8} e^{3}$

15 a

(.0) $A$ i, wo

(6) $34 \mathrm{~s}^{2}$

(2)

(c) 6 C

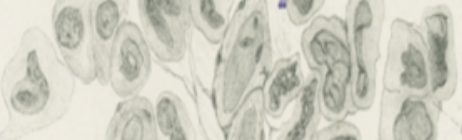

*gegrs

: 109 129

Ia

$10_{0}$ ar a 368 fy 1.50

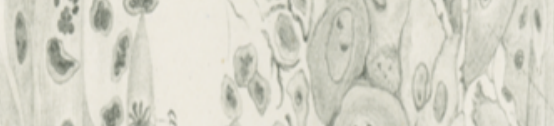

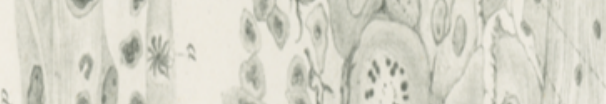
$20 \operatorname{lig}^{2}$ के की

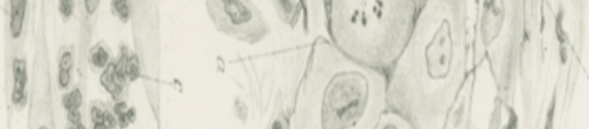

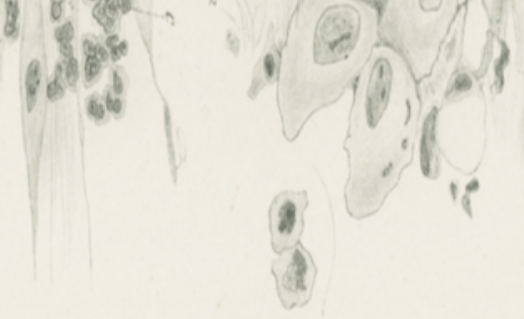

(2) $A$

a)

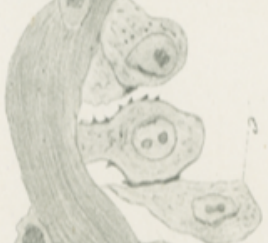

$(8)$

a.$*$.

$b^{\infty}$
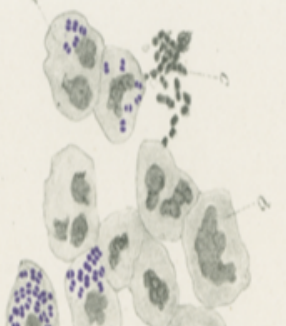

ถิ่า

6
$86197(6)$ (8) 